
2 3 14

\section{PRESTIGE AND DOMINANCE: A REVIEW OF THE DUAL EVOLUTIONARY MODEL OF SOCIAL HIERARCHY}

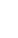

\author{
Ángel V. Jiménez ${ }^{12}$ \& Alex Mesoudi ${ }^{1}$ \\ ${ }^{1}$ Human Behaviour and Cultural Evolution Group (HuBCEG), Department of Biosciences, University \\ of Exeter Cornwall Campus \\ ${ }^{2}$ Centre for Culture and Evolution, Department of Psychology, Brunel University London \\ Correspondence should be addressed to Ángel V. Jiménez: Angel.Jimenez@brunel.ac.uk
}




\section{PRESTIGE AND DOMINANCE:}

\section{A REVIEW OF THE DUAL EVOLUTIONARY MODEL OF SOCIAL HIERARCHY}

\section{Abstract}

Twenty years ago, Joseph Henrich and Francisco Gil-White developed the dual evolutionary model of social hierarchy, which distinguishes between dominance and prestige as two different strategies to attain, maintain, and increase social rank and social influence. This model has stimulated research in various fields such as psychology, anthropology, and management science, has been useful in explaining contradictory findings in the literature, and has prompted new avenues for research. Here we review and critically evaluate the dominance-prestige model as applied to small groups without formal hierarchies. First, we outline Henrich and Gil-White's dual evolutionary model of social hierarchy. Second, we describe the evidence for and against dominance and prestige as two different strategies to acquire high social rank. Third, we discuss the long-term consequences of dominance-derived and prestigederived social rank. Fourth, we examine the biological and social consequences of attaining dominance-based and prestige-based social rank. Finally, we conclude by discussing limitations of the current literature, and suggest new avenues for research.

Key Words: Prestige, Dominance, Social Rank, Status, Social Learning, Social 4 Hierarchy, Cultural Evolution, Social Influence 
36 Twenty years ago, Joseph Henrich and Francisco Gil-White (2001) published an

37 influential article in Evolution \& Human Behaviour, which to date has received more

38 than 2000 citations. In their article, Henrich and Gil-White developed the dual evolutionary model of social hierarchy, which distinguishes between dominance and prestige as two different strategies to attain, maintain, and increase social rank and social influence. Briefly, the dominance strategy involves the use of force and coercion to elicit fear in other individuals, while the prestige strategy involves the display of competence to elicit admiration in other individuals (see below for a full description).

This distinction between dominance and prestige has stimulated research in cultural evolution (e.g. Brand \& Mesoudi, 2019; Offord, Gill, \& Kendal, 2019), social psychology (e.g. Cheng, Tracy, Foulsham, Kingstone \& Henrich, 2013; Halevy, Chou, Cohen, \& Livingston, 2012; Maner \& Case, 2016), evolutionary psychology (e.g. Conlon, 2019; Snyder, Kirkpatrick, \& Barrett, 2008), anthropology (e.g. Henrich \& Broesch, 2011; Reyes-Garcia et al., 2008; von Rueden, Gurven, \& Kaplan, 2010), and management science (McClanahan, 2019; Ronay, Maddux, \& von Hippel, 2018), it has proved useful in explaining contradictory findings in the literature (e.g. Cheng \& Tracy, 2014; Kakkar, Sivanathan, \& Gobel, 2017), and has prompted several new avenues for research (e.g., Cheng, Tracy, \& Henrich, 2010).

54 In this article, we review the literature on the dominance-prestige distinction. First, we outline Henrich and Gil-White's dual evolutionary model of social hierarchy (henceforth Dual Evolutionary Model or DEM). Second, we describe the evidence for and against dominance and prestige as two different strategies for acquiring high social rank. Third, we discuss the long-term consequences of social rank acquired via dominance 9 versus prestige. Fourth, we examine the different biological and social consequences 
60 of attaining dominance-based and prestige-based social rank. Finally, we identify

61 limitations in the current literature and suggest new avenues for research.

62 In this article, we restrict our discussion of the DEM to small groups without formal,

63 institutionalised social hierarchies such as bands of hunter-gatherers or school

64 classes. Although dominance and prestige are still relevant in large groups with formal

65 hierarchies, this goes beyond the scope of the current article. Consequently, it would

66 be unwise to generalize the DEM beyond small groups without formal hierarchies. We

67 have discussed some of the limitations of the application of the DEM to large scale

68 societies with formal hierarchies in Jiménez, Flitton, \& Mesoudi (2020) and we direct

69 interested readers to that paper.

\section{2.- The Dual Evolutionary Model of Social Hierarchy (DEM)}

71 Figure 1 depicts the DEM as applied to small groups without formal social hierarchies

72 (Cheng \& Tracy, 2014; Cheng, Tracy, Foulsham, et al., 2013; Henrich, 2016; Henrich

73 \& Gil-White, 2001; Redhead, Cheng, Driver, Foulsham, \& O'Gorman, 2018). We

74 distinguish four levels of analysis: strategies to acquire high social rank (dominance

75 strategy vs prestige strategy), dimensions of social rank (dominance dimension vs

76 prestige dimension), proximate consequences of social rank (being socially influential,

77 receiving attention and receiving deference for both the dominance and prestige

78 dimension, and being copied only for the prestige dimension), and ultimate

79 consequences of social rank (having higher fitness, which we define in evolutionary

80 terms to mean increased relative reproductive success). Table 1 provides definitions

81 of key terms in Figure 1, and other terms as we use them in this paper. 


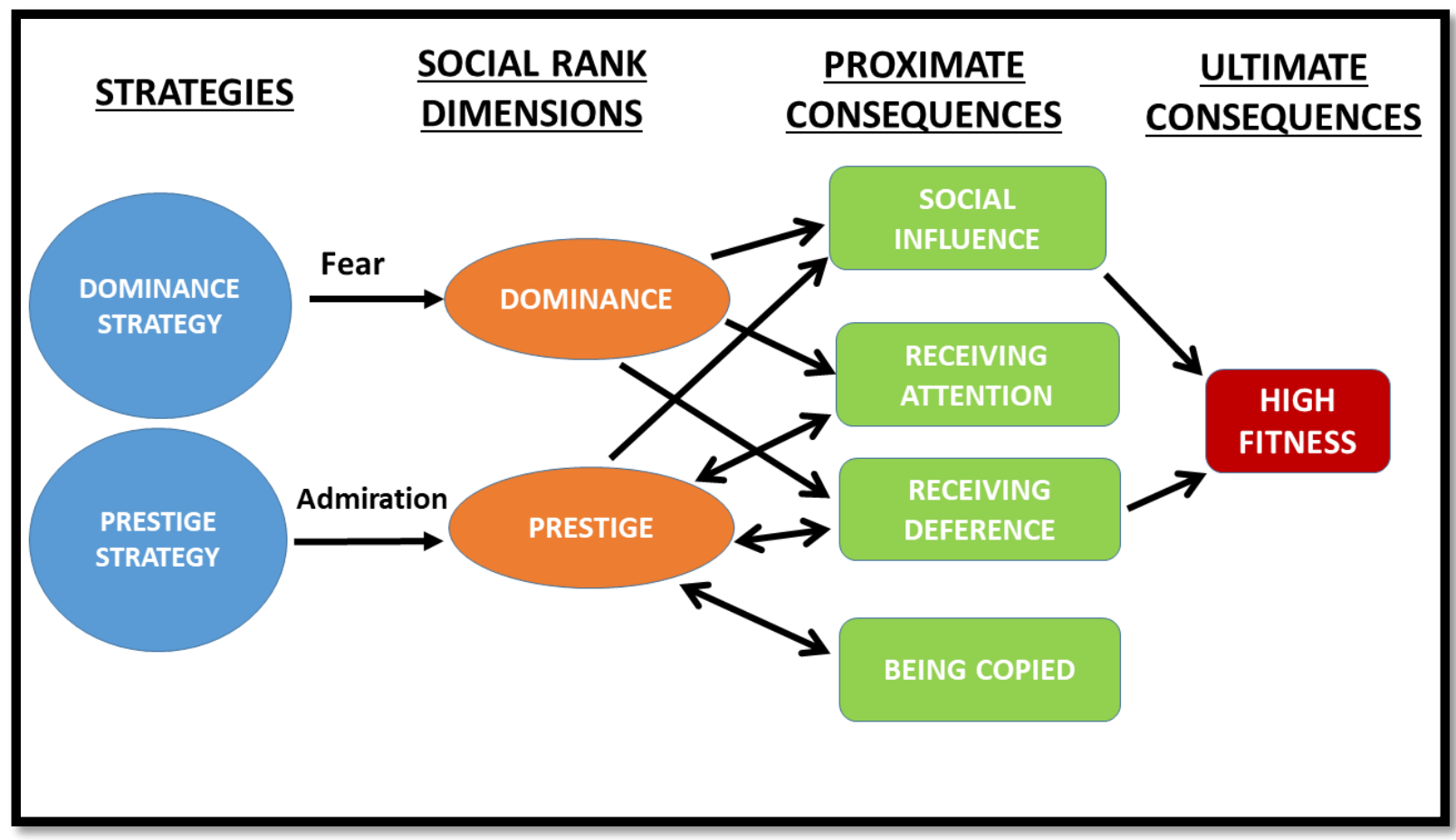

82

83 Figure 1. The Dual Evolutionary Model of Social Hierarchy (DEM) as applied to small groups without formal social 84 hierarchies. Based on Henrich and Gil-White (2001). See text for details.

85

Social Hierarchy: The ordering of individuals by their influence within a group

Social Rank: the position of an individual within a social hierarchy. High social rank individuals occupy the top of the hierarchy, while low social rank individuals occupy the bottom.

Dominance Strategy: Strategy to acquire high social rank by inflicting, or threatening to inflict, costs on other individuals within a group

Prestige Strategy: Strategy to acquire high social rank by displaying traits such as competence within a valued domain that elicit admiration by other individuals within a group

Dominance Dimension: informal social rank maintained and attained through the use of force and intimidation

Prestige Dimension: informal social rank maintained and attained through the display of valued traits such as competence within valued domains

Social influence: change of the behaviour of an individual as a consequence of the actions of others or what this individual believes are the thoughts of others

Deference: manifestations of respect and submission to the wishes of another individual

Fitness: relative reproductive success of an individual within a population 
87 According to the DEM, dominance and prestige are two strategies that people use

88 (consciously or unconsciously) to acquire, maintain, and/or increase their social rank.

89 The dominance strategy entails the display of aggressive and coercive behaviours to

90 induce fear in other individuals. The successful use of this strategy leads to the

91 acquisition of coercively imposed high social rank (dominance social rank dimension

92 in Figure 1; Cheng, 2019; Redhead, Cheng, \& O'Gorman, 2018a). In contrast, the

93 prestige strategy entails the display of knowledge/skill within valued domains to induce

94 admiration in other individuals. The successful use of this strategy leads to the

95 acquisition of voluntarily conferred high social rank (prestige social rank dimension in

96 Figure 1; Cheng, 2019; Redhead, Cheng, \& O'Gorman, 2018a). In the DEM, having a

97 position of high dominance or high prestige within a social group confers social

98 benefits, labelled 'proximate consequences' in Figure 1. Both dominant and

99 prestigious individuals are socially influential, receive preferential attention, and

100 receive deference. While these consequences are similar, they result from eliciting

101 distinct emotions in subordinates: fear for dominance, and admiration for prestige.

102 Whereas dominant individuals receive deference due to fear of the potential costs of

103 failing to do so (coerced deference), prestigious individuals receive deference due to

104 the desire of others to access their valued knowledge/skills (voluntary deference).

105 Similarly, dominant individuals are preferentially attended to in order to monitor their

106 potentially threatening behaviour, while prestigious individuals are preferentially

107 attended to due to the admiration of their knowledge/skills. The same mechanism

108 indicates that dominant individuals are socially influential through obedience, while

109 prestigious individuals are influential through persuasion.

110 A clear difference between the proximate consequences of dominance and prestige

111 is that prestige leads to being copied by other individuals, while this is not the case for 
112 dominance (see Figure 1). According to Henrich and Gil-White (2001), prestige

113 evolved in our lineage to select knowledgeable/skilful demonstrators from whom to

114 learn within valuable domains (e.g., hunting skill for a hunter-gatherer society) through

115 the use of prestige cues as a shortcut to identify competent individuals. Learning from

116 prestigious individuals would have led to the acquisition of superior knowledge/skills

117 and ultimately increased fitness. Some of these cues are first-order prestige cues, i.e.,

118 characteristics of the demonstrator such as their age and level of confidence, which

119 can be assessed directly by the observer to infer competence (Jiménez \& Mesoudi,

120 2019). However, these cues might be unreliable if, for example, some individuals are

121 over-confident or if cues like age are not perfectly correlated with knowledge/skill. This

122 would have favoured the use of second-order prestige cues, i.e. how other individuals

123 behave towards the demonstrator, such as the amount of sustained attention,

124 voluntary deference, or copying that potential demonstrators receive (Henrich \& Gil-

125 White, 2001; Jiménez \& Mesoudi, 2019). In this sense, the relationship between

126 prestige and being copied, being paid attention, and receiving deference is

127 bidirectional (see bidirectional arrows connecting prestige to being copied, receiving

128 attention, and receiving deference in Figure 1) because prestige leads to being copied,

129 receiving attention, and receiving deference, and this copying, attention, and

130 deference serves to reinforce an individual's prestige. First-order (e.g., physical

131 formidability) and second-order (e.g., fear displayed towards the target individual) cues

132 are also used for identifying who is dominant (Jiménez \& Mesoudi, 2020). The use of

133 these cues is predicted to be adaptive, as it helps to reduce potential costs by learning

134 (individually for first-order cues and socially for second-order cues) who is more likely

135 to impose those costs without having to directly suffer the dominant behaviour

136 themselves (Jiménez \& Mesoudi, 2020). 
137 Some of the proximate consequences of the dominance and prestige dimensions such

138 as being influential and receiving deference often lead to higher fitness (labelled

139 'ultimate consequences' in Figure 1) due to the fact that these result in greater access

140 to resources and mates (see arrows connecting social influence and receiving

141 deference to high fitness).

142 Although not shown in the figure, it is important to note that there might be additional

143 ways by which prestigious and dominant individuals attain higher fitness beyond the

144 proximate consequences of having higher social rank. For example, prestigious

145 individuals can acquire higher fitness directly though being highly competent in

146 important domains such as food acquisition. Similarly, some of the traits associated

147 with dominance such as physical strength in males can also lead to higher fitness if

148 this makes them more attractive to potential mates.

149 3.- Key predictions, empirical evidence, and limitations of the 150 DEM

151 In this section, we discuss the key predictions derived from the DEM (Table 2) as

152 applied to small groups without formal social hierarchies, the associated empirical

153 evidence, and its limitations.

154

155

156

157

158 


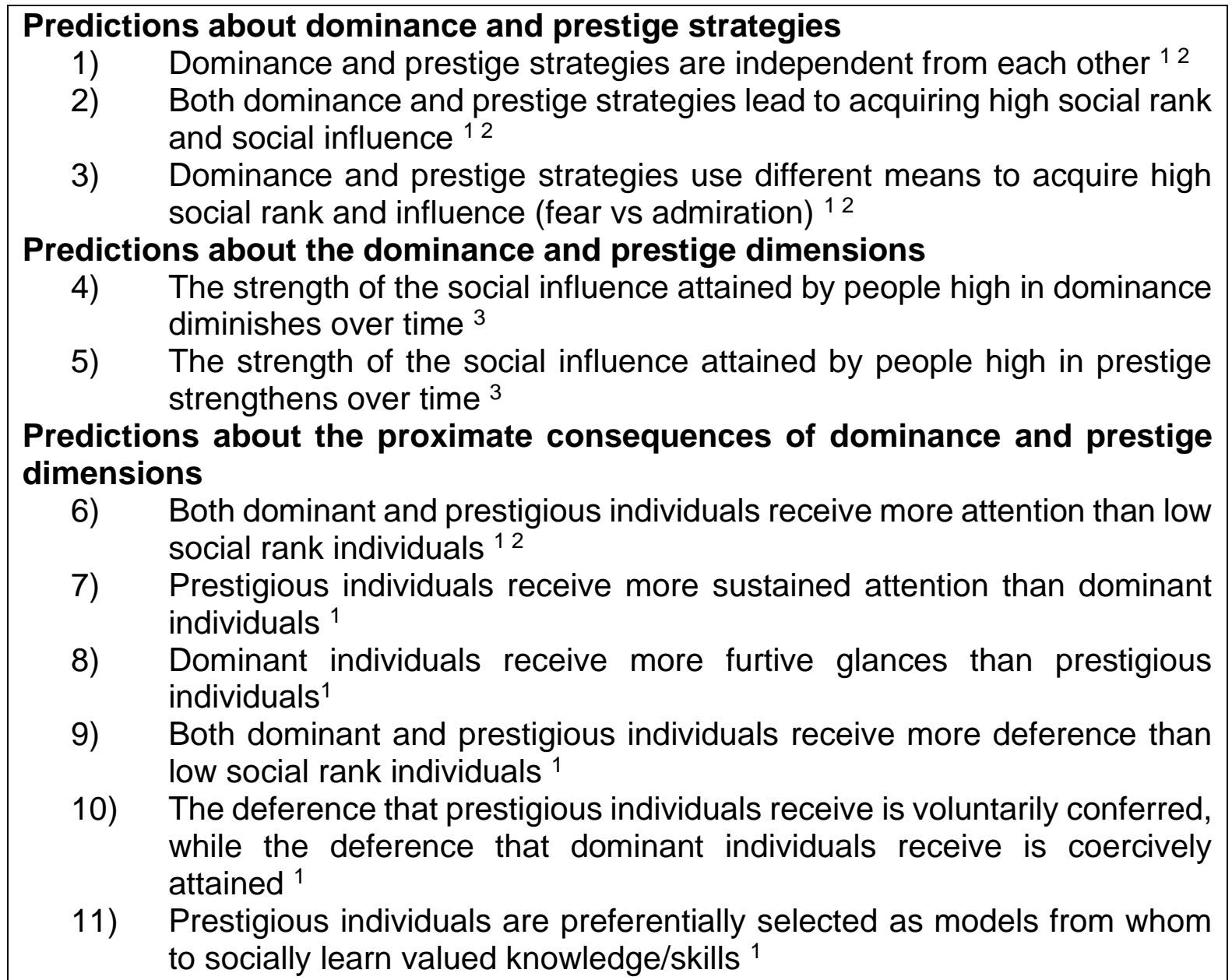

\section{Predictions about the ultimate consequences of dominance and prestige dimensions/strategies}

12) Both dominant and prestigious individuals have higher fitness than low social rank individuals ${ }^{1}$

${ }_{1}^{1}$ (Henrich \& Gil-White, 2001), ${ }^{2}$ (Cheng et al., 2013), ${ }^{3}$ (Redhead et al, 2018)

\section{1.- Strategies for attaining social rank and influence}

163 3.1.1.- Are dominance and prestige two independent strategies to the top?

164 The DEM predicts that dominance and prestige are two strategies, which are independent from each other (prediction 1 in Table 2), that both lead to acquiring high social rank and influence (prediction 2 in Table 2) but through the use of different means (fear and admiration respectively, prediction 3 in Table 2).

The standard procedure to test whether dominance and prestige are two independent strategies (prediction 1) has been to ask subjects to rate the perceived prestige and 
170 the perceived dominance of themselves or other individuals using the validated

171 Dominance-Prestige scales (Cheng, Tracy, \& Henrich, 2010). Researchers then test

172 to what extent prestige and dominance ratings are correlated, with low or non-

173 significant correlations taken as evidence of the independence of the two strategies.

174 These scales include items for dominance such as "I (he/she) enjoy(s) having control

175 over others" and "Some people are afraid of me (him/her)", and items for prestige such

176 as "Members of my (your) group respect and admire me (him/her)" and "Members of

177 my (your) group do not want to be like me (him/her)" (reverse coded). The results of

178 multiple studies using this scale, or another similar scale (Buttermore, 2006), have

179 supported the idea that prestige and dominance strategies are independent, as the

180 correlations have tended to be low (between $r=-0.06$ and $r=0.18$ ). These results have

181 been found in studies that asked participants to rate themselves (Cheng et al., 2010;

182 Conlon, 2019; Monge-López \& Álvarez-Solas, 2017); unacquainted peers in a group

183 task conducted in the laboratory (Cheng, Tracy, Foulsham, et al., 2013); peer

184 members of an athletic team (Cheng et al., 2010) or of other naturally occurring groups

185 such as music bands and colleagues working in a small businesses (Brand \& Mesoudi,

186 2019). Furthermore, low correlations between prestige and dominance are maintained

187 over time among undergraduate classmates (Redhead, Cheng, Driver, et al., 2018).

188 The prediction that both dominance and prestige strategies lead to high social rank 189 and social influence (prediction 2) has been experimentally tested by Cheng, Tracy, 190 Foulsham, et al. (2013). Students were asked to rank, first individually and later in 191 groups, the potential usefulness of fifteen pieces of equipment (e.g., box of matches, 192 signal flares, food concentrates) for surviving on the Moon (Bottger, 1984; Branch, 193 1971). Next, participants rated each other's perceived social influence, dominance, 194 prestige, and likability. Two external judges also rated each of the participants for 
195 these traits. Behavioural social influence was measured by comparing the individual 196 decisions with the collective decisions in the task. The results showed that both 197 prestige and dominance positively predicted social influence in the three measures 198 (peer ratings, external judges' ratings, and the behavioural measure). Similarly, Brand 199 and Mesoudi (2019) showed that both dominance and prestige ratings of other 200 members of naturally occurring small groups were both positively associated with 201 influence ratings within those groups.

202 These two studies also provide tentative evidence that dominance and prestige 203 strategies resulted in social influence using different means: fear vs admiration 204 respectively (prediction 3). In Cheng et al.'s study, prestige was more strongly 205 associated with liking than was dominance, and in Brand and Mesoudi's study liking 206 was positively related to prestige and negatively related to dominance. These results 207 support the idea that the prestige strategy elicits admiration and the dominant strategy 208 fear. However, being liked cannot necessarily be equated to being admired, as 209 someone could like their friends without necessarily admiring them for their 210 knowledge/skills. Similarly, being disliked cannot necessarily be equated to being 211 feared as someone could dislike an acquaintance who they find boring rather than 212 intimidating. More direct evidence for the different mechanisms that lead to high social 213 rank and influence was found in an unpublished study by Cheng, Tracy, and Henrich 214 (2013; reviewed in Cheng \& Tracy, 2014). In this study, the relationship between dominance and social influence was mediated by fear, while the relationship between prestige and social influence was mediated by contribution to the group.

217 Overall, the reviewed evidence supports the idea that dominance and prestige are two 218 independent strategies that lead to the acquisition of high social rank and social 219 influence through different means. These studies are high in external validity: they 
220 were conducted with naturally occurring groups or they studied the emergence of 221 dominance-based and prestige-based hierarchies in interactions between 222 unacquainted individuals. However, the dominance-related and prestige-related 223 behaviours were measured through self and peer reports instead of being 224 manipulated. Consequently, the nature of the supporting evidence is correlational. As 225 a next step, we encourage experiments in which dominance and prestige are 226 manipulated by the researchers (as in, for example, Kakkar, Sivanathan, \& Gobel, 227 2020), for instance by using confederates trained to use dominance and prestige cues.

228 3.1.2.- Is competence the only way to the top?

229 Our recommendation of manipulating dominance and prestige with confederates has 230 precedence in a series of studies conducted in the 1980s-90s. Contrary to prediction 2312 in Table 2, these studies found that only prestige-related cues led to the attainment 232 of social influence, while dominance-related cues failed to lead to social influence 233 (Carli, LaFleur, \& Loeber, 1995; Copeland, Driskell, \& Salas, 1995; Driskell, Olmstead, 234 \& Salas, 1993; Ridgeway, 1987; Ridgeway \& Diekema, 1989), apparently challenging 235 the dual model. In the first of these experiments (Ridgeway, 1987), a confederate 236 argued with a second confederate about a financial reward in an insurance settlement 237 while displaying non-verbal cues that indicated either dominance (e.g., loud voice, 238 tense posture, staring eye contact), submissiveness (e.g., soft voice, cowering 239 posture, averted eye contact with sneaking glances), high competence (e.g., medium 240 voice, relaxed posture, high eye contact with normal break-offs), or low competence 241 (e.g., soft, slumped voice, slumped posture, low eye contact). The target confederate 242 argued for a low reward, while the other confederate argued for an average reward. 243 Participants had to decide the amount of the financial reward before and after being 244 exposed to the interaction. The difference between these amounts was used as the 
245 measure of social influence. The results showed that the use of high competence cues

246 led to the highest level of influence, while there were no significant differences

247 between the uses of dominance, submissive, and low competence cues in predicting

248 influence.

249 However, according to Cheng and Tracy (2014), the failure of the dominance strategy

250 to attain influence in these studies was probably due to two reasons. First, the

251 dominant behaviour was not directed towards participants and, consequently, the

252 participants were unlikely to directly experience the fear which is necessary for the

253 successful use of the dominance strategy. Second, the measure of influence was

254 persuasion, which is a type of social influence characterized by convincing someone

255 who did not share a belief or idea about the superiority of such a belief/idea. The

256 change of belief through persuasion is a voluntary process and, consequently, is more

257 suited to the prestige strategy. Dominant individuals do not achieve social influence

258 through persuasion but through coercion. That is, people are submissive to the wishes

259 of dominant individuals and obey them due to fear, not because they are convinced

260 that a certain action or belief professed by the dominant individual is better.

261 Consequently, these studies only show that the dominance strategy is not useful for

262 attaining social influence through persuasion but they do not provide evidence

263 regarding whether the use of the dominance strategy is useful for attaining social

264 influence through fear and intimidation.

265 A "one-way to the top" approach has also been proposed by Chapais (2015) who 266 argues that both dominance and prestige require competence and, consequently, 267 competence is the only way to the top. For Chapais, the attainment of high social rank 268 via dominance requires competence in abilities such as controlling one's own fear, 269 using weapons, formulating tactics to attack rivals, etc. Moreover, this competence in 
270 imposing one's will, for Chapais, not only triggers fear but also admiration and,

271 consequently, the dominance-prestige distinction is not so clear-cut.

272 Although it is true that dominance goes together with competence within domains such 273 as the ones mentioned by Chapais, this is not incompatible with the DEM, which 274 focuses on the causes of acquiring high social rank and social influence through the 275 elicitation of different emotions in others. A dominant behaviour might elicit both fear 276 and admiration, but it is unlikely that these are triggered together at the same time in 277 the same individual. People suffering the dominant behaviour would defer to the 278 dominant individual due to fear. Other individuals might admire the dominant individual 279 for their dominance-related skills when they are used against other individuals, 280 especially members of rival out-groups, but not against themselves. Consistent with 281 this, Halevy et al. (2012) have shown that behaviours damaging an out-group and 282 benefitting the in-group elicit perceptions of greater prestige and lower dominance 283 amongst in-group members when there is no other way of benefitting the in-group 284 without damaging the out-group.

285 However, if the dominant behaviour were to be directed towards the in-group, it seems 286 implausible that this behaviour would elicit the admiration of in-group members or that, 287 if admiration is elicited somehow, the elicitation of admiration instead of fear would be 288 the pathway to the top. For example, terrorists might acquire social influence among 289 people with similar ideology through the prestige route due to their commitment to their 290 cause or their violence against those who they see as their enemy. However, the only 291 way they are going to acquire social influence among the people they are fighting 292 against is by imposing their will through violence and intimidation. Thus, the dual 293 pathways remain distinct. In this light, we do not think that Chapais' (2015) criticism 
294

295

296

297

298

299

300

301

302

303

304

305

306

307

308

309

310

311

312

313

314

315

316

317

318

entails a major challenge to the DEM (for further discussion about the in-group vs outgroup distinction applied to the DEM, see Jiménez, Flitton, \& Mesoudi, 2020).

\subsection{3.- Are there more strategies to the top beyond dominance and prestige?}

Numerous studies in social psychology (Flynn, 2003; Flynn, Reagans, Amanatullah, \& Ames, 2006; Hardy \& Van Vugt, 2006; Willer, 2009) have shown that altruism or generosity are associated with the attainment of high social rank and greater influence within a social group. For instance, Hardy and Van Vugt (2006) conducted a study in which participants had to decide how much of a monetary allocation to contribute to a public fund rather than keep for themselves. The money in the public fund was multiplied by a bonus factor and then divided equally among participants irrespective of their contribution. The results showed that participants who contributed more to the public fund did economically worse but were rated higher in prestige.

However, researchers do not agree whether altruism (or morality in general, which is a broader concept) is an independent way to the top (Bai, 2016), or is part of or a modifier of the prestige route (Cheng \& Tracy, 2014; Henrich, 2016). Henrich and Gil White (2001, p.180) argue that individuals who provide public goods at a cost to themselves often acquire prestige but that the advantage of defecting (i.e., using the goods without deferring to the provider) makes it difficult for prestige to evolve through altruism. Nevertheless, they point out that for skilful/knowledgeable individuals, the provision of public goods might be an excellent way to advertise their competence and, consequently, obtain a greater number of followers who defer to them, which might be translated into fitness gains. Similarly, Cheng and Tracy (2014) see altruism as a way of signalling competence to acquire more followers. They argue that the tendency to copy the prestigious is an incentive for prestigious individuals to behave altruistically, as if they are followed, they would acquire more benefits through the 
319 contribution of other individuals to the public good. This close link between being 320 altruistic and being copied has been proposed as one mechanism for the evolution of 321 human cooperation (Henrich, 2016, pp. 128-131; Henrich, Chudek, \& Boyd, 2015).

322 In contrast to subsuming altruism within competence, Bai (2016) argues that altruism 323 and other forms of moral behaviour are an independent way to acquire high social 324 rank. By morality Bai means "a prescriptive system (...) that focuses on approach 325 motives to do something good" (pp.208-209), which is usually costly for the individual 326 behaving morally. To effectively acquire high social rank, the display of moral 327 behaviour should be tuned to the morality systems accepted within a specific culture, 328 as the display of competence should be tuned to the domains that the observers 329 regard as important.

330 According to Bai, competence is not a requirement for the moral route to high social 331 rank as many heroes and heroines often fail to achieve their goals and might be 332 punished for their virtues. Bai gives the example of Malala Yousafzai, a Pakistani 333 schoolgirl who defended the right of girls to attend school against the Taliban and was 334 shot for this. Although she failed in restoring access to education for girls in Pakistan, 335 she was awarded a Nobel Prize for her heroism, which led her to become a very 336 influential person worldwide.

337 According to Bai (2016), the psychological mechanism to acquire high social rank 338 through the morality route is the elicitation of admiration for virtue, which leads to 339 positive feelings and expectations of the morally praiseworthy individuals bearing 340 costs to benefit the group or benefit a particular moral view. Consequently, people 341 accept the influence of virtuous individuals and defer to them because they believe 342 this would benefit themselves. This is very similar to the mechanism of the 
343

344

345

346

347

348

349

350

351

352

353

354

355

356

357

358

359

360

361

362

363

364

365

366

367

competence route, in which admiration for competence leads to people deferring to the competent individual to attain benefits (e.g., social learning or private/public goods) for themselves (Leary, Jongman-Sereno, \& Diebels, 2014). This suggests that displaying competence and/or displaying altruism (or other forms of morality) are ways in which people can acquire prestige and voluntary deference, rather than constituting a separate, third dimension of social rank.

Nevertheless, Bai argues that admiration is an "umbrella term" (p. 211), which refers to similar but different emotions (Schindler, Zink, Windrich, \& Menninghaus, 2013). For instance, admiration for morality leads to more intense physical sensations (e.g., warmth in the chest) and higher desire for imitating others than admiration for skill (Algoe \& Haidt, 2009). Similarly, admiration for morality and admiration for skill activate different cortical areas in the brain (Immordino-Yang, McColl, Damasio, \& Damasio, 2009). However, this does not change the fact that people admired for their competence or for their virtue are conferred voluntary deference because people expect to benefit from them, and that this contrasts with the coerced deference attained by dominant individuals.

Bai seems to have found cases in which competence is not necessary to acquire prestige. Another such case is when people who have acquired wealth through inheritance rather than competence behave altruistically. However, competence and altruism seem to be tightly linked together in many empirical contexts. For example, altruism is positively correlated with prestige (Cheng et al., 2010) and morality with competence-respect in some of Bai's own studies (Bai, Ho, \& Yan, 2019). Similarly, competence (e.g., hunting skill and gardening knowledge) and altruism (e.g., sharing meat and helping others with work) clustered together in a study with a foraging society using data reduction techniques (Konečná \& Urlacher, 2017). Furthermore, 
368

369

370

371

372

373

374

375

376 All in all, the reviewed evidence suggests that altruism/generosity (or moral behaviour

377 in general) is a way in which individuals might attain high prestige. However, further

378 research is necessary to understand how altruism/generosity interacts with

379 competence in the attainment of prestige.

380 3.1.4.- Are there multiple ways to display the dominance and prestige strategies?

381 The concept of dominance in the animal literature has been found problematic.

382 Dominance usually refers to the use of force or the threat of the use of force, 383 sometimes with the help of coalitional support (Lewis, 2002). This is also the way that 384 dominance is frequently understood in the human literature, which is associated with physical and non-verbal cues that signal the capacity of an individual to inflict costs via physical aggression such as physical formidability, masculine facial characteristics, or deeper voices, as well as behavioural displays such as risk-taking behaviour (Hill, Bailey, \& Puts, 2017; Redhead, Cheng, \& O'Gorman, 2018b). However, this is not the only way humans and other animals can impose costs on other individuals. Lewis (2002) has restricted the concept of dominance to physical dominance and has used the term 'leverage' to refer to the way individuals can attain social influence through the possession of resources that cannot be taken by force. For example, female 
393 chimpanzees have an advantageous social position when they are in oestrus, 394 although the ability to win fights does not change. In humans, expert knowledge/skills 395 and wealth can be used to inflict costs or threaten to inflict costs on others to attain 396 social influence. For example, a shaman can attain influence in others by threatening 397 to withhold his services when they are needed (Chapais, 2015).

398 Apart from the display of competence and altruism/generosity, other individual 399 behaviours and characteristics such as demographic characteristics (Berger, Cohen, 400 \& Zelditch, 1972), assertiveness (Anderson \& Kilduff, 2009b), confidence (Anderson, 401 Brion, Moore, \& Kennedy, 2012) and social connectedness (Anderson \& Shirako, 402 2008) have been associated with the attainment of prestige. We posit that 403 demographic characteristics, assertiveness, and confidence are first-order cues that 404 people use to infer competence and, therefore, prestige (Jiménez \& Mesoudi, 2019). 405 In contrast, social connectedness is a way to broadcast competence and/or generosity 406 (Anderson \& Kilduff, 2009a).

407 Anderson and Shirako (2008) demonstrated the importance of social connectedness 408 for acquiring prestige through generosity in a study with business students enrolled in 409 a negotiation class. The researchers used peer reports to measure the level of 410 connectedness of each student prior to the start of the class and the students' 411 reputations after engaging in dyadic negotiation exercises. The results show that the 412 more connected individuals' reputation for cooperativeness or selfishness was more 413 strongly linked to their history of behaviour during negotiations than the reputation of 414 less connected individuals.

415 It could be argued that social connectedness is also necessary to attain prestige 416 through competence. For example, scientific publications and scientific prestige 
417 culturally evolved to encourage scientists to share their knowledge, so that others can

418 build on it (Hull, 1988/2010). If Darwin and Wallace had kept their ideas to themselves,

419 they would not be celebrated, and natural selection would have taken longer to

420 discover.

421 3.1.5.- Conclusion on dominance and prestige strategies

422 Taking all these pieces of evidence together, we propose talking about dominance

423 and prestige strategies in the plural, instead of assuming a single dominance strategy

424 and a single prestige strategy. Within dominance strategies, we include physical

425 dominance and leverage (Lewis, 2002). Within prestige strategies, we include displays

426 of (apparent) competence, displays of (apparent) generosity, and the development of

427 social connections (Anderson \& Kilduff, 2009a).

428 Future research will need to determine to what extent the different strategies for

429 attaining dominance and prestige are independent from each other. We predict that

430 the two strategies to rank high in the dominance dimension, physical dominance and

431 leverage, are independent because their induction of fear rest on different

432 mechanisms: the capacity to win fights vs the possession of valued

433 knowledge/skills/resources (prediction 1 in Table 3). In contrast, we predict that the

434 three strategies to rank high in the prestige dimension, displaying competence,

435 displaying generosity, and developing more social connections, are more dependent

436 on each other (prediction 2 in Table 3).

1) Physical dominance and leverage are two independent strategies to induce fear in others and attain/maintain/increase social rank and social influence

2) Displaying competence, displaying generosity, and developing more social connections are not independent strategies to induce admiration and attain/maintain/increase social rank and social influence

Table 3. Predictions derived from the present review. 
437 3.2.- Dimensions of Social Rank

438 3.2.1.- The long-term consequences of the dominance and prestige dimensions

439 The DEM was initially developed to explain rank differentiation within small groups that

440 possess informal hierarchies, such as hunter-gatherer bands or groups of school

441 peers (Henrich \& Gil-White, 2001). In such groups where members know each other

442 and interact face-to-face, the use of either dominance strategies or prestige strategies

443 is an effective means to attain coercively imposed or freely conferred social rank

444 respectively (see Section 3.1). However, dominance and prestige are likely to have

445 different dynamics over time within this type of small-scale group.

446 Redhead, Cheng, Driver, et al. (2018) studied this in a longitudinal study with naturally 447 occurring small groups without formal hierarchies. They predicted that the social 448 influence attained by people initially rated as high in dominance diminishes over time 449 (prediction 4 in our Table 2), while the social influence attained by people initially rated 450 as high in prestige strengthens over time (prediction 5 in our Table 2). The rationale 451 for these predictions is a consequence of the different mechanisms by which 452 dominance and prestige operate. The elicitation of fear by dominant individuals does 453 not require prolonged observation. If a schoolchild is threatened by a bully in his first 454 day at a new school, fear is going to be elicited immediately. This makes dominance 455 effective for acquiring social influence and social rank in transient encounters or in the 456 initial stages when a group is forming. However, people dislike attacks on their 457 autonomy and being coerced to do things against their will (Boehm et al., 1993; Price 458 \& Van Vugt, 2014). Consequently, less dominant individuals often fight back against 459 dominant individuals by forming coalitions (e.g. Ridgeway \& Diekema, 1989) and, in 460 doing so, resist or diminish their influence over time. 
461 In contrast, prestige strategies need more prolonged observation to be effective. The 462 schoolchild in the example above might see one of their classmates scoring a couple 463 of goals in their first day at a new school but this might have been due to luck or the 464 incompetence of the rival players. Consequently, our schoolchild is going to need 465 further observation to develop admiration for the football skills of the classmate.

466 Redhead, Cheng, Driver, et al. (2018) conducted their study with newly formed student 467 project groups of 3-5 individuals at an American university. The students within each 468 group interacted during four hours per week for 16 weeks. Each student rated the 469 dominance, prestige, and social influence of the other students in their group on four 470 occasions during this period using the validated scales (Cheng, Tracy, Foulsham, et 471 al., 2013; Cheng et al., 2010) described in Section 3.1.1.

472 Contrary to prediction 4 in Table 2, the relationship between the initial ratings of 473 dominance and the ratings of social influence did not diminish or change over time. 474 This might have been because the groups were formed by only 3 to 5 individuals and 475 the interactions only lasted 16 weeks. It is possible that within larger groups or over 476 longer periods of time, less dominant individuals might be able to diminish the 477 influence of dominant individuals by forming larger or better organised coalitions. 478 Nevertheless, dominant individuals can also form coalitions with other individuals and, 479 if these coalitions are effective using coercion, it is not clear why dominant individuals 480 could not increase their influence over time.

481 Redhead et al. (2018) found that the relationship between the initial ratings of prestige 482 and the ratings of social influence did increase over time, which supports prediction 5 483 in Table 2. Furthermore, the authors found a bidirectional relationship between 484 prestige and social influence over time. This is congruent with the DEM as some of 
485 the consequence of prestige, such as being copied and receiving deference, make the 486 prestige of an individual and consequently their social influence increase over time 487 (see bidirectional arrows connecting being copied and receiving deference with the 488 prestige dimension in Figure 1, and Cheng, 2019 for a review).

489 Nevertheless, this longitudinal study only lasted 16 weeks. It is possible that the 490 relationship between prestige and social influence are different over longer periods of 491 time. For example, it is known that hunting performance in hunter-gatherers peaks 492 around 40 years of age (Stibbard-Hawkes, Attenborough \& Marlowe, 2018; Walker, 493 Kill, Kaplan \& McMillan, 2002). Because prestige is thought to be positively correlated 494 with competence within valued domains (Henrich \& Gil-White, 2001; Jiménez \& 495 Mesoudi, 2019), the relationship between prestige and social influence is likely to 496 strengthen over the first 30 years of hunting. However, hunting skill diminishes over 497 time after this age, and, therefore, the strength of this relationship is also likely to 498 diminish (Jiménez \& Mesoudi, 2019).

499 Little research has been conducted on the relationship between dominance or prestige 500 and social influence over time. Therefore, we cannot reach strong conclusions. We 501 have pointed out that other factors such as the size of the group, the length of time, 502 and the ability of high and low dominance individuals to form effective coalitions might 503 influence the long-term trajectories of the social influence of dominant and prestigious 504 individuals.

505 3.3.- Proximate Consequences of Dominance and Prestige

506 According to the DEM, attaining a dominance- or prestige-derived high social rank 507 leads to individuals becoming socially influential (prediction 2 in Table 2), receiving 508 attention (prediction 6 in Table 2) and receiving deference (prediction 9 in Table 2). 509 Nevertheless, these similar consequences of dominance and prestige are achieved 
510 through different means, i.e., the induction in subordinates of fear (dominance) vs

511 admiration (prestige).

\section{3.3.1.- Attention}

513 Although the DEM predicts that both dominant and prestigious individuals receive

514 preferential attention from subordinates (prediction 6 in Table 2), it also predicts that

515 the type of attention they receive is different. Prestigious individuals are expected to 516 receive sustained attention, which is assumed to facilitate the acquisition of high 517 quality knowledge/skills through social learning from competent individuals (prediction 5187 in Table 2, Henrich \& Gil-White, 2001). Dominant individuals are expected to receive 519 furtive glances, which functions to monitor the behaviour of the dominant individual to 520 prevent potential costs, while not being seen to be a threat to the dominant individual 521 or attracting negative behaviours (prediction 8 in Table 2; Henrich \& Gil-White, 2001).

522 While the evidence showing that high social rank individuals are paid more attention 523 is robust (Dalmaso, Pavan, Castelli, \& Galfano, 2012; DeWall \& Maner, 2008; 524 Foulsham, Cheng, Tracy, Henrich, \& Kingstone, 2010; Gerpott, Lehmann-Willenbrock, 525 Silvis, \& Van Vugt, 2017; Jones et al., 2010), few studies have distinguished between 526 dominant and prestigious individuals. One exception is a recent study conducted by 527 Roberts, Palermo, and Visser (2019). These researchers manipulated dominance and 528 prestige through the use of first-order cues (Jiménez \& Mesoudi, 2019; Jiménez \& 529 Mesoudi, 2020): faces rated as high or low in dominance and CVs considered to be 530 high (e.g., succeeding in a career in medicine) or low (e.g., having dropped out of 531 university) in prestige. The attentional blink task was used, which entails the rapid 532 presentation of a series of stimuli including two targets and a few distractors 533 (scrambled human faces and dog faces). This task is used to study biases affecting 534 the allocation of attentional resources to competing stimuli. In this study, participants 
535 identified the faces by answering positively to the question "did you see an 536 unscrambled face?" Contrary to prediction 6 in Table 2, there were no significant 537 differences between the high and low prestige stimuli, and the accuracy was higher 538 for low dominance stimuli than for high dominance stimuli. It is not clear why the low 539 dominance faces were more accurately identified, but a possibility suggested by the 540 authors is that the low dominance faces attracted attention because they did not meet 541 the stereotypical expectations of what male faces look like. Nevertheless, the 542 procedure involved 10 milliseconds to process each stimulus with an interval of 80 543 milliseconds between stimuli. This is very different from the way people interact with 544 dominant and prestigious individuals in real life and it is difficult to compare with other 545 attention experiments using more realistic experimental materials.

546 Another exception is the study by Cheng, Tracy, Foulsham, et al. (2013) reviewed in 547 Section 2.1, in which dominance and prestige-based hierarchies emerged in small 548 groups of unacquainted individuals completing the Moon Task. After running this task, 549 external raters wearing fixed eye-trackers viewed clips of these interactions and rated 550 the individuals in the clips for dominance and prestige. In support of prediction 6 in 551 Table 2, the dominance and prestige ratings received by the individuals in the clips 552 were positively related to the amount of perceptual attention they received by these 553 external raters.

554 Cheng et al. did not directly test whether the type of attention that dominant and 555 prestigious individuals received was different. However, they took two different 556 measures of attention: total fixation duration and proportion of fixations. These 557 measures can be used as proxies for sustained attention and furtive glances, 558 respectively. According to the standardized coefficients, dominance ratings $(\beta=.56)$ 559 positively predict sustained attention to a greater extent than prestigious ratings ( $\beta=$ 
$560.23)$, which contradicts the prediction of greater sustained attention towards 561 prestigious individuals than dominant individuals (prediction 7 in Table 2). Dominance 562 ratings $(\beta=.56)$ also positively predict furtive glances to a greater extent than prestige 563 ratings $(\beta=.24)$, which supports the prediction of a greater number of furtive glances 564 towards dominant individuals than towards prestigious individuals (prediction 8 in 565 Table 2).

566 Another relevant study was conducted by Holland, Wolf, Looser, and Cuddy (2017), 567 although there was no comparison between dominance and prestige. The authors 568 used static images of one man and one woman displaying either dominant poses (e.g., 569 greater occupation of the space and open limbs) or submissive poses (e.g., smaller 570 occupation of the space and closed limbs), while participants' attention was recorded 571 with eye-tracking devices. As the authors predicted, people fixated less and spent less 572 time looking at dominant posers than at submissive posers, fixated less and spent less 573 time looking at the faces and upper bodies, and more at the lower bodies of dominant 574 posers than submissive posers. This is congruent with the assumption that dominant 575 individuals are feared and monitored. The authors conclude their article emphasizing 576 the importance of distinguishing between prestige and dominance to assess attention 577 in line with Henrich and Gil-White's (2001) predictions. They point out that, while 578 experiments using prestige through manipulations of targets' uniforms (DeWall \& 579 Maner, 2008; Maner, DeWall, \& Gailliot, 2008) or CVs (Dalmaso et al., 2014; Dalmaso 580 et al., 2012) indicate that people pay sustained attention to high prestige individuals, 581 their manipulations of the target's dominance through non-verbal displays indicate that 582 people avert their gaze from high dominance individuals.

583 In summary, it is unclear whether prestigious and dominant individuals receive similar 584 or different types of attention. The study by Cheng et al. (2013) found that both 
585 prestigious and dominant individuals received similar types of attention and that 586 dominance has a stronger effect than prestige in predicting both sustained attention 587 and furtive glances. However, Holland et al. (2017) showed that people avert their 588 gaze from people displaying dominant poses, which suggests that people do show 589 different types of attention towards dominant individuals. Unfortunately, this study did 590 not compare dominance with prestige. Moreover, these eye-tracking experiments 591 have the limitation that they measure the attention paid to individuals differing in social 592 rank by external observers to the group interactions. The DEM predicts that dominant 593 individuals should only encourage furtive glances when the dominant individuals can 594 react to the observer. Similarly, prestigious individuals should only encourage 595 sustained attention when it is possible to learn something valuable (e.g., knowledge, 596 skill) from them. Neither of these were possible in these experiments. The introduction 597 of expectations about encountering these high social rank individuals or being watched 598 by them later (e.g., Gobel, Kim, \& Richardson, 2015) might help to clarify this question. 599 Furthermore, the development of mobile eye-tracking devices that allow the 600 measurement of attentional biases of participants interacting together is promising. 601 Future studies using mobile eye-trackers in group interactions might help to tell apart 602 the effects of prestige and dominance on social attention.

603 3.3.2.- Deference

604 The DEM predicts that both dominant and prestigious individuals should receive more 605 deference than low social rank individuals (prediction 9 in Table 2). It also predicts that 606 the deference received by dominant individuals is coercively attained due to the fear 607 of potential costs (e.g., physical aggression) of failing to do so in subordinates, while 608 the deference received by prestigious individuals is voluntarily conferred due to the 609 wish of subordinates to benefit from the prestigious individual's knowledge/skill 
610 (prediction 10 in Table 2). Unfortunately, to our knowledge, there are no studies

611 comparing the deference received by dominant and prestigious individuals.

612 Deference towards dominant men has been shown in an experiment about mate 613 competition (Gambacorta \& Ketelaar, 2013). In this experiment, male participants were 614 made to believe that they were competing with another man for a date with an 615 attractive woman. Dominance was manipulated via a photo of a shirtless man who 616 was either physically strong (high dominance) or weak (low dominance). Participants 617 were prompted to tell stories and jokes to the attractive woman. Gambacorta and 618 Ketelaar assumed that dominant men have used violence to prevent other men mate 619 through human evolutionary history. Consequently, men competing for mates with a 620 dominant man would inhibit creative displays to avoid the potential costs inflicted by 621 dominant individuals. As predicted, men competing with the high dominance man told 622 fewer stories and jokes than the men competing with the low dominance man. 623 Moreover, the quality of the stories and jokes of the men who told them was lower 624 when competing with the high dominance man than when competing with the low 625 dominance man.

626 Deference towards prestigious individuals has been shown by van der Vegt, 627 Bunderson, and Oosterhof (2006), who found that participants with low expertise in a 628 group task showed more deference (i.e., were more committed and showed more 629 help) towards experts than towards less competent individuals. This could be 630 interpreted as a way to incentivise experts to provide more contributions, advice and 631 help (Jiménez \& Mesoudi, 2019). 
633 3.3.3.- Social learning

634 A clear difference between the proximate consequences of dominance and prestige

635 is that prestige leads to being preferentially selected as a demonstrator from whom to 636 socially learn valuable knowledge/skills (prediction 11). This is not the case for 637 dominance except perhaps when the knowledge/skill that is socially learned is the 638 dominance strategy itself. This prediction is derived from Henrich and Gil-White's 639 (2001) theory of the evolution of prestige, which was reviewed in Section 2.

640 This preferential selection of prestigious individuals as demonstrators from whom to 641 socially learn has been demonstrated by laboratory and online experiments (Atkisson, 642 O'Brien, \& Mesoudi, 2012; Brand, Heap, Morgan, \& Mesoudi, 2020; Chudek, Heller, 643 Birch, \& Henrich, 2012) and by ethnographic studies of small-scale societies (Henrich 644 \& Broesch, 2011; Henrich \& Henrich, 2010). Although the experimental evidence 645 generally supports the use of prestige-biased social learning, there is little supporting 646 evidence in the ethnographic record (Garfield, Garfield, \& Hewlett, 2016; Garfield, 647 Hubbard, \& Hagen, 2019). Similarly, Chudek, Baron, and Birch (2016) did not find 648 that children aged 2-7 preferentially copied high prestige individuals over low prestige 649 individuals. See Jiménez and Mesoudi (2019) for a full review of prestige-biased social 650 learning.

\section{3.4. Ultimate Consequences of Dominance and Prestige}

652 3.4.1.- Higher Fitness

653 The DEM predicts that both dominant and prestigious individuals have higher fitness

654 than lower social rank individuals (prediction 12 in Table 2). We define fitness in 655 evolutionary terms as the relative reproductive success of individuals within a social 656 group. The predicted higher reproductive success of dominance and prestige 657 individuals can either be a consequence of a direct link between genetic 658 predispositions towards prestige/dominance psychology and reproductive success, or 
659 a human behavioural ecology approach where it is assumed that people generally 660 maximise their fitness, and prestige and dominance are two ways in which this is done 661 without needing to necessarily assume genetic predispositions for prestige-dominance 662 specifically.

663 von Rueden et al. (2010) studied whether this prediction holds for Tsimane men. The 664 ability to win a dyadic physical confrontation was used as a proxy for dominance, while 665 community-wide influence was used as a proxy for prestige. Both dominance and 666 prestige were positively related to number of in-pair surviving offspring and extra667 marital affairs. Both correlations were stronger for prestige. Dominance was positively 668 related to marrying younger women and prestige to having wives with earlier age of 669 birth. The relationship between determinants of social rank (physical formidability, 670 political influence, and hunting ability) and positive fertility outcomes is robust in the 671 literature regarding small-scale foraging societies (Von Rueden, 2014). Nevertheless, 672 it is less clear how dominant and prestigious individuals attain higher fertility. Von 673 Rueden (2014) suggests that it could be through having more access to mates and/or 674 higher quality mates, as well as receiving more support from allies and deference from 675 others. It is also possible that the characteristics that lead to attaining high social rank 676 within these societies (e.g., hunting ability) are the important factors in determining 677 offspring survivorship (Von Rueden, 2014). Moreover, it could also be the case that 678 having more offspring is what leads to attaining higher social rank and not the other 679 way round (Von Rueden, 2014).

680 Sexual preferences for dominant and prestigious men have also been found in studies 681 with WEIRD (acronym for Western, Educated, Industrialized, Rich and Democratic; 682 Henrich, Heine, \& Norenzayan, 2010) samples. Snyder et al. (2008) argue that high 683 dominance men could cause costs to their partners if they behave aggressively 
684 towards them. Consequently, they hypothesized that women generally prefer 685 prestigious men over dominant men. They independently manipulated dominance 686 (high vs low) and prestige (high vs low) in a $2 \times 2$ between-subjects design using 687 descriptions of individuals competing for leadership within a student fraternity. They 688 found support for their hypothesis: high prestige individuals were rated as more 689 attractive and desirable as short-term and long-term partners than low prestige 690 individuals. Low dominance individuals were also more desirable as long-term 691 partners than high dominance individuals. In a subsequent study using the context of 692 an athletic competition, high dominance men were considered more attractive and 693 desirable as both short-term and long-term partners than low dominance men. A 694 potential explanation for this finding is that using the dominance strategy in athletic 695 male to male competition is socially sanctioned (Snyder et al., 2008) and, therefore, it 696 could be difficult to disentangle it from the prestige strategy of displaying high 697 competence. Unfortunately, there was no comparison between prestige and 698 dominance in the athletic context in this study.

699 From our point of view, the prediction that dominant and prestigious individuals have 700 higher fitness than lower social rank individuals might depend on the time over which 701 dominant and prestigious individuals are able to maintain their high social rank. If 702 dominant individuals are not able to maintain high social rank over longer periods of 703 time as predicted in prediction 4 in Table 2, their short-term dominance is unlikely to 704 pay off in terms of fitness. Similarly, if the prestige of an individual does not last for 705 long, or it is in a domain that is not widely appreciated by members of the other sex, 706 high prestige might not be translated into higher fitness. 
708 In this article we have reviewed the literature regarding key predictions derived from 709 Henrich and Gil-White's Dual Evolutionary Model of Social Hierarchy as applied to 710 human social groups without formal hierarchies (see predictions 1-12 in Table 2) and 711 suggested new predictions for research (see predictions (1-2) in Table 3). The 712 literature is largely supportive of the model, but the DEM has generated some 713 controversies regarding whether a dual model of social hierarchy is the most 714 appropriate way to capture social rack acquisition processes (see Section 3.1.), and 715 there are considerable gaps in the literature regarding the different proximate and 716 ultimate consequences of dominance and prestige (see Sections. 3.3. and 3.4.)

717 The evidence is generally supportive of the idea that dominance and prestige are two 718 independent strategies that lead to the acquisition of high social rank and influence 719 (predictions 1-2 in Table 2). The different mechanisms that supposedly explain the 720 acquisition of social rank using dominance and prestige strategies are the elicitation 721 of fear and admiration in other individuals, respectively (prediction 3 in Table 2). 722 Although this is a central component of the DEM, this is an area of research that has 723 been largely neglected. Furthermore, the debates on whether there are two pathways 724 to the top as the DEM posits, or only one, or more than two, could be solved if further 725 scrutiny is dedicated to the similar or different mechanisms that lead to the acquisition 726 of higher social rank through different strategies.

727 In our view, there are more than two strategies for attaining high social rank (see 728 Section 3.1.3), but these strategies can nevertheless be classified into dominance 729 strategies and prestige strategies in the plural depending on the emotions that they 730 elicit in other individuals. If they elicit fear, they are dominance strategies. If they elicit 731 admiration, they are prestige strategies. We posit that dominance strategies, i.e. 
732 physical dominance and leverage, are two independent strategies to induce fear in

733 others based on different mechanisms: the capacity to win contests vs the possession

734 of valued knowledge/skills/resources (dominance strategies, prediction 1 in table 2).

735 We posit that the prestige strategies, i.e. displaying competence, displaying 736 generosity/morality, and developing social connections, are more dependent on each 737 other (prediction 2 in Table 3). For example, individuals would need certain level of 738 generosity to be admired for their competence, and competent individuals would 739 require social connections to be seen, which is a prerequisite for gathering admiration. 740 The dependence / independence of different dominance and prestige strategies are 741 important areas of research that require further attention by researchers of social rank 742 acquisition.

743 The DEM states that both dominant and prestigious individuals receive more attention 744 (prediction 5 in Table 2) and deference (prediction 7 in Table 2) than low social rank 745 individuals. There is little controversy over the fact that this is the case. The DEM also 746 states that the types of attention (predictions 6-7 in Table 2) and deference (predictions 747 8-9 in Table 2) that dominant and prestigious individuals receive are different and are 748 the consequence of the different emotions they supposedly elicit in other individuals: 749 fear vs admiration (prediction 3 in Table 2). Unfortunately, there is no research directly 750 comparing the different types of attention and deference that dominant and prestigious 751 individuals receive. Research in this area would benefit from studying simultaneously 752 the emotions elicited in other individuals (see above in this section) and their 753 behavioural manifestations: sustained attention and voluntary deference in prestigious 754 individuals vs furtive glances and coerced deference in dominant individuals, 755 respectively. 
756 Given the fact that Henrich and Gil-White (2001) consider that social learning is the

757 selective pressure that led to the evolution of prestige in humans, it is not surprising 758 that social learning from prestigious individuals is one of the most studied 759 consequences of having high prestige (Jiménez \& Mesoudi, 2019). Unfortunately, 760 studies comparing social learning from dominant and prestigious individuals has not 761 yet been conducted. We encourage researchers to study the conditions under which 762 people preferentially copy dominant individuals. For example, people might copy 763 elements of the dominance strategy itself from dominant individuals if they have 764 previously seen that dominant individuals attain what they want and that this has no 765 negative consequences for them.

766 In conclusion, the DEM has become one of the most influential evolutionary theories

767 of social hierarchies in humans. Nevertheless, many important predictions of the 768 model still need to be appropriately tested. We hope that this article stimulates 769 research on the missing pieces of this puzzle. 
776 5.- Acknowledgements

777 This research was supported by the Leverhulme Trust (grant RPG-2016-122658

778 awarded to AM). We thank Thomas Currie, Rick O'Gorman, Matt Gobel, and Alice 779 Williams for their comments in earlier versions of this manuscript.

780

781

782

783

784

785

786

787

788

789

790

791

792

793 
794

795

796

797

798

799

800

801

802

803

804

805

806

807

808

809

810

811

812

813

814

815

816

817

818

\section{6.- References}

Anderson, C., Brion, S., Moore, D. A., \& Kennedy, J. A. (2012). A Status-Enhancement Account of Overconfidence. Journal of Personality and Social Psychology, 103(4), 718-735.

Anderson, C., \& Kilduff, G. J. (2009a). The Pursuit of Status in Social Groups. Current Directions in Psychological Science, 18(5), 295-298. doi:10.1111/j.14678721.2009.01655.x

Anderson, C., \& Kilduff, G. J. (2009b). Why do dominant personalities attain influence in face-to-face groups? The competence-signaling effects of trait dominance. Journal of Personality and Social Psychology, 96(2), 491-503. doi:10.1037/a0014201

Anderson, C., \& Shirako, A. (2008). Are individuals' reputations related to their history of behavior? J Pers Soc Psychol, 94(2), 320-333. doi:10.1037/00223514.94 .2 .320

Atkisson, C., O'Brien, M. J., \& Mesoudi, A. (2012). Adult learners in a novel environment use prestige-biased social learning. Evol Psychol, 10(3), 519-537.

Bai, F. (2016). Beyond Dominance and Competence: A Moral Virtue Theory of Status Attainment. Personality and Social Psychology Review, 21(3), 203-227. doi:10.1177/1088868316649297

Bai, F., Ho, G. C. C., \& Yan, J. (2019). Does virtue lead to status? Testing the moral virtue theory of status attainment. $J$ Pers Soc Psychol. doi:10.1037/pspi0000192

Berger, J., Cohen, B. P., \& Zelditch, M. (1972). Status Characteristics and Social Interaction. American Sociological Review, 37(3), 241-255. doi:10.2307/2093465 
819 Blader, S. L., \& Chen, Y.-R. (2014). What's in a Name? Status, Power, and Other Forms of Social Hierarchy. In J. T. Cheng, J. L. Tracy, \& C. Anderson (Eds.), The Psychology of Social Status (pp. 71-95). New York, NY: Springer New York.

Boehm, C., Barclay, H. B., Dentan, R. K., Dupre, M.-C., Hill, J. D., Kent, S., . . Rayner, S. (1993). Egalitarian Behavior and Reverse Dominance Hierarchy [and Comments and Reply]. Current Anthropology, 34(3), 227-254. doi:doi:10.1086/204166

Bottger, P. C. (1984). EXPERTISE AND AIR TIME AS BASES OF ACTUAL AND PERCEIVED INFLUENCE IN PROBLEM-SOLVING GROUPS. Journal of Applied Psychology, 69(2), 214-221. doi:10.1037/0021-9010.69.2.214

Branch, L. G. (1971). Individual Versus Triadic Performance on a Multidimensional Complementary Task as a Function of Initial Ability Level. Dissertations, Paper 1165.

Brand, C. O., Heap, S., Morgan, T. J., \& Mesoudi, A. (2020). The adaptive use of prestige-biased social learning in an online, knowledge-based task. Scientific Reports 10 (12095).

Brand, C. O., \& Mesoudi, A. (2019). Prestige and dominance-based hierarchies exist in naturally occurring human groups, but are unrelated to task-specific knowledge. Royal Society Open Science, 6(5), 181621. doi:10.1098/rsos.181621

Buttermore, N. (2006). Distinguishing dominance and prestige: Validation of a selfreport scale. Paper presented at the Poster presented at the Human Behavior and Evolution Society's 18th Annual Meeting. Philadelphia, Pennsylvania. 
843 Carli, L. L., LaFleur, S. J., \& Loeber, C. C. (1995). Nonverbal behavior, gender, and influence. Journal of Personality and Social Psychology, 68(6), 1030.

845

846

847

848

849

850

851

852

853

854

855

856

857

858

859

860

861

862

863

864

865

866

867

Chapais, B. (2015). Competence and the Evolutionary Origins of Status and Power in Humans. Human Nature-an Interdisciplinary Biosocial Perspective, 26(2), 161183. doi:10.1007/s12110-015-9227-6

Cheng, J. T. (2019). Dominance, Prestige, and the Role of Leveling in Human Social Hierarchy and Equality. Current Opinion in Psychology. doi:https://doi.org/10.1016/j.copsyc.2019.10.004

Cheng, J. T., \& Tracy, J. L. (2014). Toward a Unified Science of Hierarchy: Dominance and Prestige are Two Fundamental Pathways to Human Social Rank. 3-27. doi:10.1007/978-1-4939-0867-7_1

Cheng, J. T., Tracy, J. L., Foulsham, T., Kingstone, A., \& Henrich, J. (2013). Two ways to the top: evidence that dominance and prestige are distinct yet viable avenues to social rank and influence. J Pers Soc Psychol, 104(1), 103-125. doi:10.1037/a0030398

Cheng, J. T., Tracy, J. L., \& Henrich, J. (2010). Pride, personality, and the evolutionary foundations of human social status. Evolution and Human Behavior, 31(5), 334347. doi:10.1016/j.evolhumbehav.2010.02.004

Cheng, J. T., Tracy, J. L., \& Henrich, J. (2013). Dominance promotes social rank via heightened fear, not by group contribution. [Manuscript in Preparation]. University of British Columbia.

Chudek, M., Baron, A. S., \& Birch, S. (2016). Unselective Overimitators: The Evolutionary Implications of Children's Indiscriminate Copying of Successful and Prestigious Models. Child Development, 87(3), 782-794. doi:10.1111/cdev.12529 
868 Chudek, M., Heller, S., Birch, S., \& Henrich, J. (2012). Prestige-biased cultural learning: bystander's differential attention to potential models influences children's learning. Evolution and Human Behavior, 33, 46-56.

Conlon, K. E. (2019). Mate Retention Strategies of Dominance-Oriented and PrestigeOriented Romantic Partners. Evolutionary Psychological Science. doi:10.1007/s40806-019-00189-x

Copeland, C. L., Driskell, J. E., \& Salas, E. (1995). Gender and reactions to dominance. Journal of Social Behavior and Personality, 10(4), 53.

Dalmaso, M., Pavan, G., Castelli, L., \& Galfano, G. (2012). Social status gates social attention in humans. Biology Letters, 8(3), 450-452. doi:10.1098/rsbl.2011.0881

DeWall, C. N., \& Maner, J. K. (2008). High Status Men (But Not Women) Capture the Eye of the Beholder. Evolutionary Psychology, 6(2), 328-341.

Driskell, J. E., Olmstead, B., \& Salas, E. (1993). Task cues, dominance cues, and influence in task groups. Journal of Applied Psychology, 78(1), 51.

Flynn, F. J. (2003). How Much Should I Give and How Often? The Effects of Generosity and Frequency of Favor Exchange on Social Status and Productivity. The Academy of Management Journal, 46(5), 539-553. doi:10.2307/30040648

Flynn, F. J., Reagans, R. E., Amanatullah, E. T., \& Ames, D. R. (2006). Helping one's way to the top: self-monitors achieve status by helping others and knowing who helps whom. J Pers Soc Psychol, 91(6), 1123-1137. doi:10.1037/00223514.91.6.1123 
891 Foulsham, T., Cheng, J. T., Tracy, J., Henrich, J., \& Kingstone, A. (2010). Gaze

892

893

894

895

896

897

898

899

900

901

902

903

904

905

906

907

908

909

910

911

912

913

914 Allocation in a Dynamic Social Situation of Social Status and Speaking. Cognition, 117, 319-331.

Fragale, A. R., Overbeck, J. R., \& Neale, M. A. (2011). Resources versus respect: Social judgments based on targets' power and status positions. Journal of Experimental Social Psychology, 47(4), $\quad$ 767-775. doi:http://doi.org/10.1016/j.jesp.2011.03.006

Gambacorta, D., \& Ketelaar, T. (2013). Dominance and deference: Men inhibit creative displays during mate competition when their competitor is strong. Evolution and Human Behavior, 34(5), 330-333. doi:10.1016/j.evolhumbehav.2013.05.003

Garfield, Z. H., Garfield, M. J., \& Hewlett, B. S. (2016). A Cross-Cultural Analysis of Hunter-Gatherer Social Learning. In H. Terashima \& B. S. Hewlett (Eds.), Social Learning and Innovation in Contemporary Hunter-Gatherers: Evolutionary and Ethnographic Perspectives (pp. 19-34). Tokyo: Springer Japan.

Garfield, Z. H., Hubbard, R. L., \& Hagen, E. H. (2019). Evolutionary Models of Leadership. Human Nature. doi:10.1007/s12110-019-09338-4

Gerpott, F. H., Lehmann-Willenbrock, N., Silvis, J. D., \& Van Vugt, M. (2017). In the eye of the beholder? An eye-tracking experiment on emergent leadership in team interactions. The Leadership Quarterly. doi:https://doi.org/10.1016/.leaqua.2017.11.003

Grant, A. (2013). Give and take. Why helping others drives our success. Croydon: Orion Books.

Halevy, N., Chou, E. Y., Cohen, T. R., \& Livingston, R. W. (2012). Status Conferral in Intergroup Social Dilemmas: Behavioral Antecedents and Consequences of 
Prestige and Dominance. J Pers Soc Psychol, 102(2), 351-366. doi:10.1037/a0025515

Hardy, C. L., \& Van Vugt, M. (2006). Nice Guys Finish First: The Competitive Altruism Hypothesis. Personality and Social Psychology Bulletin, 32(10), 1402-1413. doi:10.1177/0146167206291006

Hays, N. A. (2013). Fear and loving in social hierarchy: Sex differences in preferences for power versus status. Journal of Experimental Social Psychology, 49(6), 1130-1136. doi:10.1016/j.jesp.2013.08.007

Hays, N. A., \& Bendersky, C. (2015). Not all inequality is created equal: Effects of status versus power hierarchies on competition for upward mobility. J Pers Soc Psychol, 108(6), 867-882. doi:10.1037/pspi0000017

Henrich, J. (2016). The secret of our success : how culture is driving human evolution, domesticating our species, and making us smarter. Princeton, New Jersey :: Princeton University Press.

Henrich, J., \& Broesch, J. (2011). On the nature of cultural transmission networks: evidence from Fijian villages for adaptive learning biases. Philosophical Transactions of the Royal Society B-Biological Sciences, 366(1567), 11391148. doi:10.1098/rstb.2010.0323

Henrich, J., \& Gil-White, F. J. (2001). The evolution of prestige: freely conferred deference as a mechanism for enhancing the benefits of cultural transmission. Evolution and Human Behavior, 22(3), 165-196. doi:10.1016/S1090$5138(00) 00071-4$

Henrich, J., Heine, S. J., \& Norenzayan, A. (2010). The weirdest people in the world? Behav Brain Sci, 33(2-3), 61-83; discussion 83-135. doi:10.1017/s0140525x0999152x 
940 Henrich, J., \& Henrich, N. (2010). The evolution of cultural adaptations: Fijian food taboos protect against dangerous marine toxins. Proceedings of the Royal Society B: Biological Sciences. doi:10.1098/rspb.2010.1191

Hill, A., Bailey, D., \& Puts, D. (2017). Gorillas in Our Midst? Human Sexual Dimorphism 944 and Contest Competition in Men.

945 Holland, E., Wolf, E. B., Looser, C., \& Cuddy, A. (2017). Visual attention to powerful 946 postures: People avert their gaze from nonverbal dominance displays. Journal

948 949

950 951

952

953 954 955

956 of Experimental Social Psychology, 68, 60-67. doi:10.1016/j.jesp.2016.05.001

Hull, D. L. (1988/2010). Science as a process: an evolutionary account of the social and conceptual development of science: University of Chicago Press.

Jiménez, Á. V., Flitton, A., \& Mesoudi, A. (2020, January 7). When do people prefer dominant over prestigious political leaders? Retrieved from https://doi.org/10.31219/osf.io/68zca

Jiménez, Á. V., \& Mesoudi, A. (2019). Prestige-biased social learning: current evidence and outstanding questions. Palgrave Communications, 5(1), 20. doi:10.1057/s41599-019-0228-7

Jiménez, Á. V., \& Mesoudi, A. (2020). The cultural transmission of prestige and dominance social rank cues: an experimental investigation. Evolutionary psychological science. https://doi.org/10.1007/s40806-020-00261-x

Jones, B. C., DeBruine, L. M., Main, J. C., Little, A. C., Welling, L. L. M., Feinberg, D. R., \& Tiddeman, B. P. (2010). Facial cues of dominance modulate the shortterm gaze-cuing effect in human observers. Proceedings of the Royal Society B: Biological Sciences, 277(1681), 617-624. doi:10.1098/rspb.2009.1575 
963 Kakkar, H., \& Sivanathan, N. (2017). When the appeal of a dominant leader is greater

964

965

966

967

968

969

970

971

972

973

974

975

976

977

978

979

980

981

982

983

984

985

986

than a prestige leader. Proceedings of the National Academy of Sciences, 114(26), 6734-6739. doi:10.1073/pnas.1617711114

Kakkar, H., Sivanathan, N., \& Gobel, M. S. (2020). Fall from grace: The role of dominance and prestige in the punishment of high-status actors. Academy of Management Journal, O(ja), null. doi:10.5465/amj.2017.0729

Leary, M. R., Jongman-Sereno, K. P., \& Diebels, K. J. (2014). The pursuit of status: A self-presentational perspective on the quest for social value. . In J. T. Cheng, J. L. Tracy, \& C. Anderson (Eds.), The psychology of social status (pp. 158178). New York, NY: Springer.

Lewis, R. J. (2002). Beyond dominance: the importance of leverage. Q Rev Biol, 77(2), 149-164.

Magee, J. C., \& Galinsky, A. D. (2008). 8 social hierarchy: The self-reinforcing nature of power and status. Academy of Management annals, 2(1), 351-398.

Maner, J. K., \& Case, C. R. (2016). Chapter Three - Dominance and Prestige: Dual Strategies for Navigating Social Hierarchies. In M. O. James \& P. Z. Mark (Eds.), Advances in Experimental Social Psychology (Vol. Volume 54, pp. 129180): Academic Press.

McClanahan, K. J. (2019). Viva la evolution: Using dual-strategies theory to explain leadership in modern organizations. The Leadership Quarterly, 101315. doi:https://doi.org/10.1016/j.leaqua.2019.101315

Monge-López, D., \& Álvarez-Solas, S. (2017). Self-perceived social status: its relation to aggression and personality traits in two Spanish speaking samples. Actualidades en Psicología, 31(123), 1-11. doi:10.15517/ap.v31i123.26441 
Offord, M., Gill, R., \& Kendal, J. (2019). The effects of prestige on collective performance and information flow in a strictly hierarchical institution. Palgrave Communications, 5(1), 4. doi:10.1057/s41599-018-0211-8

Price, M. E., \& Van Vugt, M. (2014). The evolution of leader-follower reciprocity: the theory of service-for-prestige. Frontiers in Human Neuroscience, 8(363). doi:10.3389/fnhum.2014.00363

Redhead, D., Cheng, J. T., Driver, C., Foulsham, T., \& O'Gorman, R. (2018). On the dynamics of social hierarchy: A longitudinal investigation of the rise and fall of prestige, dominance, and social rank in naturalistic task groups. Evolution and Human Behavior. doi:10.1016/j.evolhumbehav.2018.12.001

Redhead, D., Cheng, J. T., \& O'Gorman, R. (2018a). Higher Status in Group. In S. T \& W.-S. V (Eds.), Encyclopedia of Evolutionary Psychological Science. New York: Springer.

Redhead, D., Cheng, J. T., \& O'Gorman, R. (2018b). Individuals that Impose Costs. In T. K. Shackelford \& V. A. Weekes-Shackelford (Eds.), Encyclopedia of Evolutionary Psychological Science (pp. 1-6). Cham: Springer International Publishing.

Reyes-Garcia, V., Molina, J. L., Broesch, J., Calvet, L., Huanca, T., Saus, J., . . . McDade, T. W. (2008). Do the aged and knowledgeable men enjoy more prestige? A test of predictions from the prestige-bias model of cultural transmission. Evolution and Human Behavior, 29(4), 275-281. doi:http://dx.doi.org/10.1016/j.evolhumbehav.2008.02.002

Ridgeway, C. L. (1987). Nonverbal behavior, dominance, and the basis of status in task groups. American Sociological Review, 683-694. 
1011 Ridgeway, C. L., \& Diekema, D. (1989). Dominance and collective hierarchy formation in male and female task groups. American Sociological Review, 79-93.

1013 Roberts, A., Palermo, R., \& Visser, T. A. W. (2019). Effects of dominance and prestige based social status on competition for attentional resources. Scientific Reports, 9(1), 2473. doi:10.1038/s41598-019-39223-0

Ronay, R., Maddux, W. W., \& von Hippel, W. (2018). Inequality rules: Resource distribution and the evolution of dominance- and prestige-based leadership. The Leadership Quarterly. doi:https://doi.org/10.1016/j.leaqua.2018.04.004

Snyder, J. K., Kirkpatrick, L. A., \& Barrett, H. C. (2008). The dominance dilemma: Do women really prefer dominant mates? Personal Relationships, 15(4), 425-444. doi:10.1111/j.1475-6811.2008.00208.x

1022

1023

1024

1025

1026

1027

1028

1029

1030

1031

1032

1033

1034

Stibbard-Hawkes, D. N. E., Attenborough, R. D., \& Marlowe, F. W. (2018). A noisy signal: To what extent are Hadza hunting reputations predictive of actual hunting skills? Evolution and Human Behavior, 39(6), 639-651. doi:https://doi.org/10.1016/j.evolhumbehav.2018.06.005

van der Vegt, G. S., Bunderson, J. S., \& Oosterhof, A. (2006). Expertness Diversity and Interpersonal Helping in Teams: Why those who Need the Most Help End Up Getting the Least. Academy of Management Journal, 49(5), 877-893. doi:10.5465/amj.2006.22798169

Von Rueden, C. (2014). The roots and fruits of social status in small-scale human societies. In The psychology of social status (pp. 179-200): Springer.

von Rueden, C., Gurven, M., \& Kaplan, H. (2010). Why do men seek status? Fitness payoffs to dominance and prestige. Proceedings of the Royal Society B: Biological Sciences. doi:10.1098/rspb.2010.2145 
1035 Walker, R., Hill, K., Kaplan, H., \& McMillan, G. (2002). Age-dependency in hunting 1036 ability among the Ache of Eastern Paraguay. Journal of Human Evolution, 1037 42(6), 639-657. doi:http://dx.doi.org/10.1006/jhev.2001.0541

1038 Willer, R. (2009). Groups Reward Individual Sacrifice: The Status Solution to the 1039 Collective Action Problem. American Sociological Review, 74(1), 23-43.

1040

1041

1042

1043

1044

1045

1046

1047

1048

1049 